\title{
Rotating-platform TKA No Different from Fixed-bearing TKA Regarding Survivorship or Performance: A Meta-analysis
}

\author{
Joseph T. Moskal MD, Susan G. Capps PhD
}

Received: 3 October 2013/ Accepted: 18 February 2014/Published online: 4 March 2014

(C) The Association of Bone and Joint Surgeons \& 2014

\begin{abstract}
Background Mobile bearings have been compared with fixed bearings used in TKA. However, rotating platforms, a specific type of mobile bearing, have not been compared with fixed-bearings using meta-analysis.

Questions/purposes We asked whether the performance of a rotating-platform bearing is superior to, comparable to, or worse than a fixed bearing. Four areas were investigated: clinical performance, component alignment, adverse event rates, and revision rates.

Methods Searches of Medline, EMBASE, Google Scholar, and the Cochrane databases, combined with reference lists from published meta-analyses and systematic reviews
\end{abstract}

One or more of the authors (JTM) has received funding from DePuy, a Johnson \& Johnson Company (Warsaw, IN, USA); Zimmer (Warsaw, IN, USA); and Medtronic (Minneapolis, IN, USA). One or more of the authors (SGC) has received funding from DePuy, a Johnson \& Johnson Company.

All ICMJE Conflict of Interest Forms for authors and Clinical Orthopaedics and Related Research editors and board members are on file with the publication and can be viewed on request.

Clinical Orthopaedics and Related Research neither advocates nor endorses the use of any treatment, drug, or device. Readers are encouraged to always seek additional information, including FDAapproval status, of any drug or device prior to clinical use.

This work was performed at Carilion School of Medicine, Roanoke, VA, USA, and BENSOL, Warsaw, IN, USA.

Electronic supplementary material The online version of this article (doi:10.1007/s11999-014-3539-4) contains supplementary material, which is available to authorized users.

J. T. Moskal

Virginia Tech Carilion School of Medicine, Roanoke, VA, USA

S. G. Capps $(\square)$

BENSOL, 488 East Bell Drive, Warsaw, IN 46582, USA

e-mail: sgc@sgcappsphd.com of mobile-bearing versus fixed-bearing prostheses used in TKAs, provided 17 nonlanguage-restricted studies consisting of 1910 TKAs (966 rotating platform versus 944 fixed bearing). Random-effect modeling was used for all meta-analyses, thereby mitigating possible effects of heterogeneity among studies. All meta-analyses were examined for publication bias using funnel plots; publication bias was not detected for any meta-analysis.

Results There were no statistically or clinically significant differences in clinical performance (clinical scores, ROM, and radiographic evaluation), component alignment, revision rates, or adverse event rates except for tibial component alignment in the AP plane, which favored TKA with fixed-bearings $(\mathrm{p}=0.020$; standardized mean difference, 0.229 ; 95\% CI, 0.035-0.422), but the effect size was small enough that it was not considered clinically important.

Conclusions Based on our findings, which agree substantially with those of prior systematic reviews of TKAs with mobile-bearing versus fixed-bearing prostheses, there is no compelling case for either rotating-platform or fixedbearing implant design in terms of clinical performance, component alignment, adverse event frequencies, or survivorship. This dataset, which was limited to a maximum 6 years followup, is insufficient to address questions related to wear or late revisions. We therefore suggest that implant choice should be made on the basis of other factors, perhaps including cost or surgeon experience.

\section{Introduction}

The purported benefits of a TKA with a mobile-bearing prosthesis stem from better biomechanics and more natural 
kinematics leading to reduced polyethylene wear and reduced incidence of osteolysis and thus better performance $[4-6,21,28,30,42]$. However, it is important to understand that the term "mobile-bearing" refers to various designs, differing in their mobility: rotating-platform designs allow for free rotation of the tibial polyethylene insert about the central axis of the tibia, meniscal-bearing designs attempt to mimic the natural meniscus with independent movement of medial and lateral bearings, and AP glide-and-rotation designs allow for gliding in the AP plane and some rotation about the central axis of the tibia [6].

Although there are numerous articles directly comparing mobile- and fixed-bearing designs, including nine metaanalyses $[6,14,17,24,27,28,37,38,42]$, the distinction between mobile-bearing subgroups rarely is made. Carothers et al. [6] performed a meta-analysis examining the differences between mobile-bearing subgroups and found that TKAs with meniscal-bearing and rotating-platform prostheses did not perform as well as AP glide-and-rotation prostheses.

Given the lack of conclusive differences between TKAs with mobile-bearing and fixed-bearing prostheses, and given the observations of Carothers et al. [6], we sought to perform a systematic review and meta-analysis to look at a single type of mobile-bearing design, the rotating-platform subgroup, and compare it with fixed-bearing designs.

The overarching goal was to determine whether the performance of a TKA with a rotating-platform prosthesis is superior to, comparable to, or worse than the performance of a TKA with a fixed-bearing prosthesis, by evaluating four specific endpoints: (1) clinical performance (clinical scores, ROM, and radiographic evaluation); (2) component alignment; (3) adverse event rates; and (4) revision rates (and thus survivorship).

\section{Search Strategy and Criteria}

A literature search using Medline, EMBASE, Google Scholar, and Cochrane databases was conducted to identify all articles published between January 1990 and May 2013 that evaluated the outcome of patients undergoing a TKA using either a rotating-platform or fixed-bearing prosthesis. Search terms were: "total knee" and ["mobile bearing" or "rotating-platform"] and ["fixed-bearing" or "meta-analysis" or "systematic review"]. The reference lists of systematic reviews and meta-analyses were screened for possible additional studies. Included publications were comparative studies of TKAs with rotating-platform and fixed-bearing prostheses (not language restricted). No attempts were made to discover unpublished data.

We identified 677 potential citations (553 from systematic searches and 124 from reference lists), and after

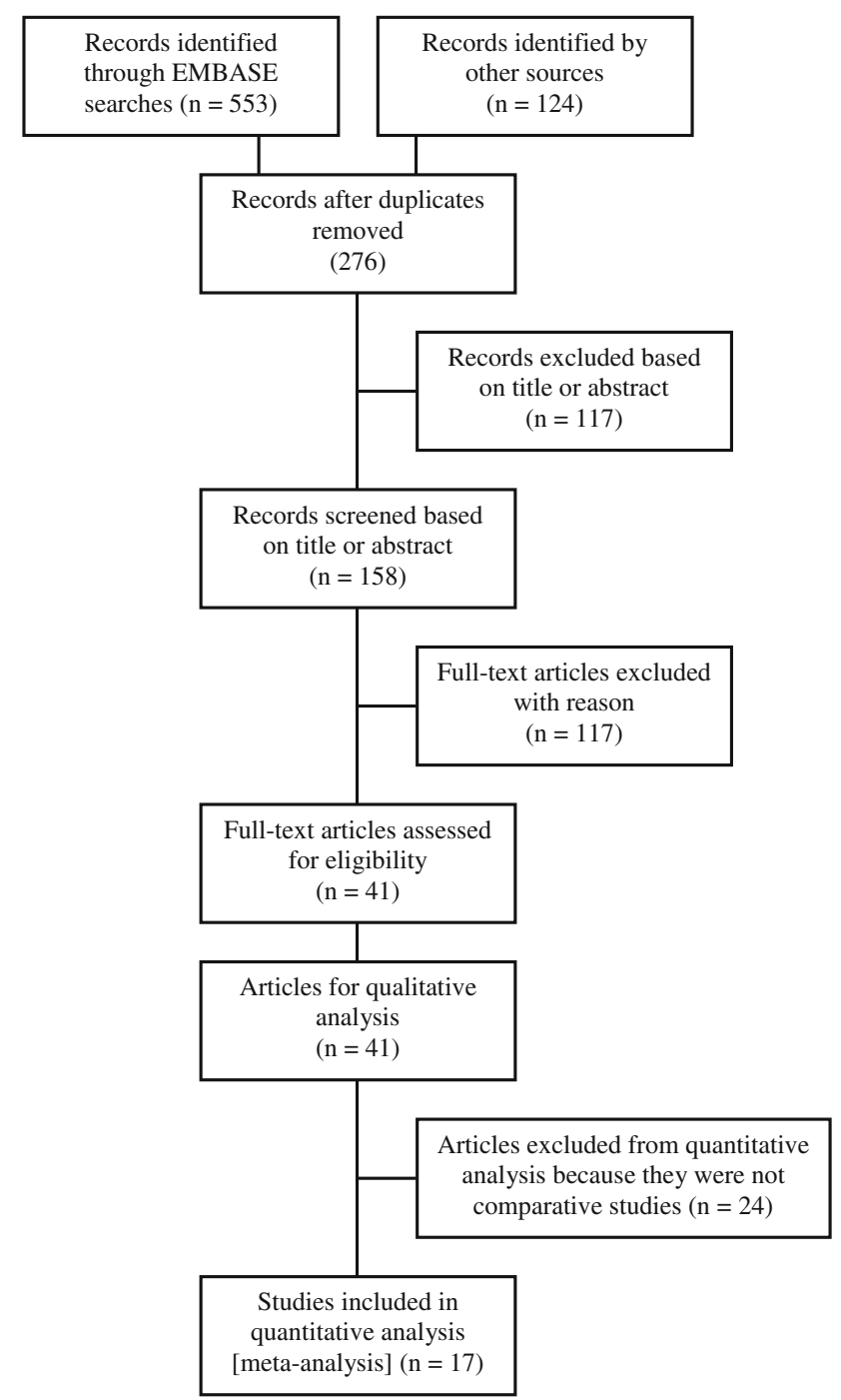

Fig. 1 The flow diagram shows the number of studies found for this meta-analysis and systematic review and the number remaining after exclusion criteria were applied.

removing duplicates there were 276 potential records (Fig. 1). These records were evaluated first by title and abstract using a single inclusion criteria: TKA with a rotating-platform compared with a fixed-bearing prosthesis; if it was uncertain, then full-text versions were screened. Two reviewers (JTM, SGC) independently reviewed the 41 studies meeting this criteria; rejection of possible sources required agreement of both authors. Each study was rated for level of evidence at the time of data extraction based on the Centre for Evidence Based Medicine (Oxford, UK) guideline [15]. Multiple publications of the same population were pooled as one study (kinship) to the extent possible to avoid double-counting cases and creating undue bias in the data set.

There are 41 articles included in this study, 22 of these providing background information [4-6, 14, 16-19, 21, 24, 
Table 1. Details of the included studies

\begin{tabular}{|c|c|c|c|c|c|c|c|c|}
\hline Study & Year & $\begin{array}{l}\text { Level of } \\
\text { evidence }\end{array}$ & $\begin{array}{l}\text { Data } \\
\text { points }\end{array}$ & $\begin{array}{l}\text { Number } \\
\text { of TKAs }\end{array}$ & Implant & $\mathrm{M} / \mathrm{F}$ & $\begin{array}{l}\text { Age (years), } \\
\text { mean }\end{array}$ & $\begin{array}{l}\text { Followup } \\
\text { (years), mean }\end{array}$ \\
\hline Aggarwal \& Agrawal [1] & 2013 & II & $\mathrm{AE}$ & & & & & \\
\hline Fixed bearing & & & & 27 & Duracon $^{\mathrm{TM}}$ & $4 / 23$ & 54.6 & 5.5 \\
\hline Rotating platform & & & & 29 & Scorpio ${ }^{\circledR}$ Plus Single Axis & $5 / 24$ & 60 & 5.6 \\
\hline Ball et al. [2] & 2011 & II & $\mathrm{AE}, \mathrm{AKS}$ & & & & & \\
\hline Fixed bearing & & & SF-12 & 42 & Scorpio $^{\circledR}$ PS & $18 / 23$ & 64 & 4.0 \\
\hline Rotating platform & & & & 51 & Scorpio $^{\circledR}$ Plus Single Axis & $22 / 28$ & 64.9 & 4.0 \\
\hline Bhan et al. [3] & 2005 & II & $\mathrm{AE}, \mathrm{AKS}$ & & & & & \\
\hline Fixed bearing & & & Rev, ROM & 32 & Insall-Burstein II & $10 / 22$ & 63 & 6.0 \\
\hline Rotating platform & & & & 32 & $\mathrm{LCS}^{\circledR} \mathrm{RP}$ & $10 / 22$ & 63 & 6.0 \\
\hline Chen et al. [7] & 2013 & II & HSS, ROM & & & & & \\
\hline Fixed bearing & & & & 97 & Genesis II $^{\mathrm{TM}}$ \& PFC Sigma ${ }^{\circledR}$ & $23 / 70$ & 64.4 & 2.7 \\
\hline Rotating platform & & & & 106 & PFC Sigma $^{\circledR}$ RP & $20 / 82$ & 67.6 & 2.7 \\
\hline Chiu et al. [8] & 2001 & II & AKS, ROM & & & & & \\
\hline Fixed bearing & & & & 16 & AMK & $2 / 14$ & 68 & 2.0 \\
\hline Rotating platform & & & & 16 & $\operatorname{LCS}^{\circledR} \mathrm{RP}$ & $2 / 14$ & 68 & 2.0 \\
\hline Evans et al. [10] & 2006 & III & AE, Rev, & & & & & \\
\hline Fixed bearing & & & $\mathrm{ROM}$ & 100 & PFC Sigma $^{\circledR}$ & $34 / 66$ & 67.7 & 2.0 \\
\hline Rotating platform & & & & 113 & PFC Sigma ${ }^{\circledR}$ RP & $51 / 62$ & 63.4 & 2.0 \\
\hline Hanusch et al. [11] & 2010 & II & $\mathrm{AE}, \mathrm{AKS}$ & & & & & \\
\hline Fixed bearing & & & Rev, ROM & 55 & PFC Sigma $^{\circledR}$ & $33 / 22$ & 69.4 & 1.1 \\
\hline Rotating platform & & & & 50 & PFC Sigma ${ }^{\circledR}$ RP & $20 / 30$ & 70 & 1.1 \\
\hline Harrington et al. [12] & 2009 & II & $\mathrm{AE}, \mathrm{AKS}$ & & & & & \\
\hline Fixed bearing & & & Rev, ROM & 72 & PFC Sigma ${ }^{\circledR}$ & $22 / 50$ & 63.3 & 2.0 \\
\hline Rotating platform & & & & 68 & PFC Sigma ${ }^{\circledR}$ RP & $28 / 40$ & 63.7 & 2.0 \\
\hline Hasegawa et al. [13] & 2009 & II & $\mathrm{AE}, \mathrm{AKS}$ & & & & & \\
\hline Fixed bearing & & & Rev, ROM & 25 & PFC Sigma ${ }^{\circledR}$ & $3 / 22$ & 73 & 3.3 \\
\hline Rotating platform & & & & 25 & PFC Sigma ${ }^{\circledR}$ RP & $3 / 22$ & 73 & 3.3 \\
\hline Jawed et al. [20] & 2012 & II & $\mathrm{AE}, \mathrm{AKS}$ & & & & & \\
\hline Fixed bearing & & & Rev, ROM & 50 & PFC Sigma ${ }^{\circledR}$ & $10 / 40$ & 64.46 & 3.3 \\
\hline Rotating platform & & & & 50 & PFC Sigma ${ }^{\circledR}$ RP & $10 / 40$ & 64.46 & 3.3 \\
\hline Kalisvaart et al. [22] & 2012 & II & $\mathrm{AE}, \mathrm{AKS}$, & & & & & \\
\hline Fixed bearing & & & Rev, ROM & 76 & PFC Sigma $^{\circledR}$ & $24 / 56$ & 67.1 & 5.3 \\
\hline Rotating platform & & & & 76 & PFC Sigma ${ }^{\circledR}$ RP & $24 / 56$ & 67.4 & 5.3 \\
\hline Kim et al. [23] & 2012 & II & $\mathrm{AE}, \mathrm{AKS}$, & & & & & \\
\hline Fixed bearing & & & HSS, ROM & 40 & NexGen ${ }^{\circledR}$ LPS Flex & $1 / 39$ & 66 & 2.5 \\
\hline Rotating platform & & & & 40 & PFC Sigma ${ }^{\circledR}$ RP-F & $2 / 38$ & 68 & 2.6 \\
\hline Lizaur-Utrilla et al. [25] & 2012 & II & AKS, Rev, & & & & & \\
\hline Fixed bearing & & & ROM, & 58 & Multigen Plus & $11 / 47$ & 73.9 & 2.5 \\
\hline Rotating platform & & & SF-12 & 61 & Trekking ${ }^{\circledR}$ MB & $14 / 47$ & 74.6 & 2.5 \\
\hline Luring et al. [26] & 2006 & III & AKS, ROM & & & & & \\
\hline Fixed bearing & & & & 20 & PFC Sigma $^{\circledR}$ & $6 / 14$ & 69 & 2.0 \\
\hline Rotating platform & & & & 20 & PFC Sigma ${ }^{\circledR}$ RP & $6 / 14$ & 67 & 2.0 \\
\hline Rahman et al. [34] & 2009 & II & AE, ROM, & & & & & \\
\hline Fixed bearing & & & SF-12 & 27 & PFC Sigma $^{\circledR}$ & $9 / 18$ & 62 & 3.3 \\
\hline Rotating platform & & & & 27 & PFC Sigma ${ }^{\circledR}$ RP & $10 / 14$ & 62.6 & 3.6 \\
\hline
\end{tabular}


Table 1. continued

\begin{tabular}{|c|c|c|c|c|c|c|c|c|}
\hline Study & Year & $\begin{array}{l}\text { Level of } \\
\text { evidence }\end{array}$ & $\begin{array}{l}\text { Data } \\
\text { points }\end{array}$ & $\begin{array}{l}\text { Number } \\
\text { of TKAs }\end{array}$ & Implant & $\mathrm{M} / \mathrm{F}$ & $\begin{array}{l}\text { Age (years), } \\
\text { mean }\end{array}$ & $\begin{array}{l}\text { Followup } \\
\text { (years), mean }\end{array}$ \\
\hline Shemshaki et al. [36] & 2012 & II & $\mathrm{AE}, \mathrm{AKS}$, & & & & & \\
\hline Fixed bearing & & & Rev & 150 & PFC Sigma $^{\circledR}$ & $48 / 102$ & 70 & 5.0 \\
\hline Rotating platform & & & & 150 & PFC Sigma ${ }^{\circledR}$ RP & $60 / 90$ & 68 & 5.0 \\
\hline Tibesku et al. [39] & 2011 & II & HSS, ROM & & & & & \\
\hline Fixed bearing & & & & 17 & Genesis II $^{\mathrm{TM}}$ & $5 / 12$ & 66 & 2.0 \\
\hline Rotating platform & & & & 16 & Genesis II $^{\mathrm{TM}} \mathrm{MB}$ & 7/9 & 65 & 2.0 \\
\hline
\end{tabular}

Level of evidence = Oxford Centre for Evidence-based Medicine determination [15], Level II = lesser-quality randomized controlled trial or prospective comparative study; Level III = retrospective comparative study; AE = Adverse events (complications), AKS = American Knee Society, HSS = Hospital for Special Surgery knee score, Rev = revisions, SF-12 = Short Form-12; Duracon ${ }^{\mathrm{TM}}$ (Stryker, Kalamazoo, MI, USA); Scorpio ${ }^{\circledR}$ (Stryker, Kalamazoo, MI, USA); Insall-Burstein II (Zimmer Inc, Warsaw, IN, USA); NexGen ${ }^{\circledR}$ (Zimmer Inc, Warsaw, IN, USA); LCS ${ }^{\mathbb{R}}$ RP (DePuy Synthes, Warsaw, IN, USA); Genesis ${ }^{\mathrm{TM}}$ (Smith \& Nephew Inc, Memphis, TN, USA); PFC Sigma ${ }^{\mathbb{R}}$ (DePuy Synthes, Warsaw, IN, USA); AMK (Depuy, Warsaw, IN, USA); MultiGen (Lima Corporate, Udine, Italy); Trekking ${ }^{\mathbb{R}}$ (SAMO, Bologna, Italy).

Table 2. Studies evaluated using the modified Jadad score

\begin{tabular}{|c|c|c|c|c|c|c|c|c|c|}
\hline Study & $\begin{array}{l}\text { Random } \\
\text { Yes }=1 \\
\text { No }=0\end{array}$ & $\begin{array}{l}\text { R method } \\
\text { Yes }=1 \\
\text { No }=-1 \\
\text { Not described }=0\end{array}$ & $\begin{array}{l}\text { Blinded } \\
\text { Yes }=1 \\
\text { No }=0\end{array}$ & $\begin{array}{l}\text { B Method } \\
\text { Yes }=1 \\
\text { No }=-1 \\
\text { Not described }=0\end{array}$ & $\begin{array}{l}\text { LTFU } \\
\text { Yes }=1 \\
\text { No }=0\end{array}$ & $\begin{array}{l}\text { Inclusion/ } \\
\text { exclusion } \\
\text { Yes }=1 \\
\text { No }=0\end{array}$ & $\begin{array}{l}\text { Adverse } \\
\text { events } \\
\text { Yes }=1 \\
\text { No }=0\end{array}$ & $\begin{array}{l}\text { Statistical } \\
\text { method } \\
\text { Yes }=1 \\
\text { No }=0\end{array}$ & Total \\
\hline Aggarwal \& Agrawal [1] & 1 & 0 & 1 & 1 & 1 & 1 & 1 & 1 & 7 \\
\hline Ball et al. [2] & 1 & 0 & 1 & 1 & 1 & 1 & 1 & 1 & 7 \\
\hline Bhan et al. [3] & 1 & 1 & 0 & 0 & 1 & 1 & 1 & 1 & 6 \\
\hline Chen et al. [7] & 1 & 0 & 0 & 0 & 1 & 1 & 0 & 0 & 3 \\
\hline Chiu et al. [8] & 0 & 0 & 0 & 0 & 1 & 1 & 1 & 1 & 4 \\
\hline Evans et al. [10] & 0 & 0 & 0 & 0 & 1 & 1 & 1 & 1 & 4 \\
\hline Hanusch et al. [11] & 1 & 1 & 0 & 0 & 1 & 1 & 1 & 1 & 6 \\
\hline Harrington et al. [12] & 1 & 0 & 0 & 0 & 1 & 1 & 1 & 1 & 5 \\
\hline Hasegawa et al. [13] & 1 & 1 & 1 & 1 & 0 & 1 & 1 & 1 & 7 \\
\hline Jawed et al. [20] & 1 & 1 & 0 & 0 & 1 & 1 & 1 & 1 & 6 \\
\hline Kalisvaart et al. [22] & 1 & 1 & 0 & 0 & 1 & 1 & 1 & 1 & 6 \\
\hline Kim et al. [23] & 1 & 1 & 0 & 0 & 1 & 1 & 1 & 1 & 6 \\
\hline Lizaur-Utrilla et al. [25] & 1 & 1 & 1 & 1 & 1 & 1 & 1 & 1 & 8 \\
\hline Luring et al. [26] & 0 & 0 & 0 & 0 & 1 & 1 & 1 & 1 & 4 \\
\hline Rahman et al. [34] & 1 & 1 & 1 & 1 & 1 & 1 & 1 & 1 & 8 \\
\hline Shemshaki et al. [36] & 1 & 1 & 0 & 0 & 1 & 1 & 1 & 1 & 6 \\
\hline Tibesku et al. [39] & 1 & 1 & 1 & 1 & 1 & 1 & 1 & 1 & 8 \\
\hline
\end{tabular}

Random = Was the study described as randomized?; R method $=$ Was the method of randomization appropriate?; Blinded = Was the study described as blinded?; B method = Was the method of blinding appropriate?; LTFU = Lost to followup, was there a description of withdrawals and dropouts?; Inclusion/exclusion = Was there a description of the inclusion/exclusion criteria?; Adverse events = Was the method used to assess adverse events described?; Statistical method = Was the method of statistical analysis described?

$27,28,30-33,35,37,38,40-42], 17$ are included in the quantitative analysis, also known as meta-analysis $[1-3,7$, $8,10-13,20,22,23,25,26,34,36,39]$, and the remaining two provide measures of level of evidence and modified Jadad score $[15,29]$. Of the 17 studies, 15 were Level of
Evidence II (randomized controlled trials without blinding or prospective comparative studies) $[1-3,7,8,11-13,20$, $22,23,25,34,36,39]$ with a total of 1657 TKAs (833 in the rotating-platform group and 824 in the fixed-bearing group) and two were Level of Evidence III (retrospective 
Table 3. Meta-analysis results for clinical scores

\begin{tabular}{|c|c|c|c|c|c|c|}
\hline $\begin{array}{l}\text { Clinical scores at } \\
\text { final followup }\end{array}$ & $\mathrm{p}$ value & $\begin{array}{l}\text { Standard difference } \\
\text { in means } \\
(95 \% \mathrm{CI})\end{array}$ & $\begin{array}{l}\text { Heterogeneity } \\
\text { p value }\end{array}$ & $\begin{array}{l}\text { Heterogeneity } \\
I^{2} \%\end{array}$ & $\begin{array}{l}\text { Number } \\
\text { of TKAs }\end{array}$ & $\begin{array}{l}\text { Number } \\
\text { of studies }\end{array}$ \\
\hline The Knee Society Function & 0.465 & $0.073(-0.123$ to 0.270$)$ & 0.045 & $51.19 \%$ & 932 & 8 \\
\hline The Knee Society Knee Score & 0.429 & $-0.116(-0.405$ to 0.172$)$ & 0.000 & $80.01 \%$ & 1052 & 10 \\
\hline Hospital for Special Surgery & 0.510 & $0.075(-0.149$ to 0.300$)$ & 0.475 & $0 \%$ & 307 & 3 \\
\hline SF-12 Physical & 0.501 & $0.172(-0.329$ to 0.672$)$ & 0.019 & $74.63 \%$ & 263 & 3 \\
\hline SF-12 Mental & 0.209 & $0.249(-0.139$ to 0.637$)$ & 0.092 & $58.14 \%$ & 263 & 3 \\
\hline
\end{tabular}

Table 4. Range of motion

\begin{tabular}{llcllll}
\hline $\begin{array}{l}\text { ROM at final } \\
\text { followup }\end{array}$ & $\mathrm{p}$ value & $\begin{array}{l}\text { Standard difference } \\
\text { in means }(95 \% \mathrm{CI})\end{array}$ & $\begin{array}{l}\text { Heterogeneity } \\
\mathrm{p} \text { value }\end{array}$ & $\begin{array}{l}\text { Heterogeneity } \\
I^{2} \%\end{array}$ & $\begin{array}{l}\text { Number of } \\
\text { TKAs }\end{array}$ & $\begin{array}{l}\text { Number of } \\
\text { studies }\end{array}$ \\
\hline Flexion contracture & 0.848 & $0.024(-0.223$ to 0.272$)$ & 0.492 & $0 \%$ & 252 & 4 \\
Extension & 0.499 & $-0.060(-0.235$ to 0.115$)$ & 0.708 & $0 \%$ & 503 & 3 \\
Flexion & 0.058 & $0.136(-0.004$ to 0.276$)$ & 0.333 & $12.20 \%$ & 940 & 9 \\
Total ROM & 0.685 & $0.037(-0.143$ to 0.218$)$ & 0.110 & $40.31 \%$ & 853 \\
\hline
\end{tabular}

comparative studies) $[9,26]$ with a total of 253 TKAs (133 in the rotating-platform group and 120 in the fixed-bearing group) (Table 1). Included studies were evaluated using the modified Jadad score [29], the average score for quality was 5.9 of 8 possible points (Table 2).

Data were extracted independently after all the eligible studies were recruited using a data abstraction form (Appendix 1. Supplemental material is available with the online version of CORR); all data regarding participant and clinical outcome were recorded for analysis. Participant data included the number of TKAs, and patient age and sex. The principal outcomes of interest, appearing in at least three sources, included clinical performance at final followup (The Knee Society scores, Hospital for Special Surgery, and SF-12 Physical and Mental Components, ROM, and radiolucent lines), component alignment, reported complications (anterior knee pain, patellar tilt, and manipulation for stiffness), and revision rates. Clinical performance scores were not normalized for comparison across scoring measures; each is presented as reported without additional mathematical manipulation.

Study-specific odds ratio and associated 95\% CIs account for discontinuous variables, which were pooled using random-effect modeling.

Standardized mean difference or weighted mean difference was used for continuous variables using randomeffect modeling. Heterogeneity was tested using Cochran's Q-test, expressed as p value and $I^{2}$, and it was determined that the fixed-effects modality was inappropriate (larger $I^{2}$ indicates increasing heterogeneity and thus the need for random-effects modeling). Publication bias was tested for each variable using funnel plots and Duval and Tweedie's trim and fill method [9] to impute missing studies; no publication bias was detected. Statistical analyses were performed with Comprehensive Meta Analysis (Version 2.2.064 for Windows; Biostat Inc, Englewood, NJ, USA) or with JMP (Version 10.0 for Mac, SAS Institute Inc, Cary, NC, USA) when the incidences of particular events (for example, revisions, osteolysis, and loosening) were often zero for either the rotating-platform group or the fixedbearing group; significance for all statistical analyses was defined as $\mathrm{p}$ less than 0.05 .

\section{Outcome Measurements}

The results of odds ratio/standardized mean difference or 95\% CI for each comparison for clinical results (Table 3), ROM (Table 4), radiographic evaluation (Table 5), incident (Table 6), component alignment (Table 7), and adverse events (Table 8) are shown. As usual in the orthopaedic literature, there was a lack of consistency regarding followup; results were obtained from directly pooling the data without stratifying for time Moreover, not all studies provided the same types of data; thus, there is the possibility of bias in the final results. 
Table 5. Radiographic evaluation

\begin{tabular}{|c|c|c|c|c|c|c|}
\hline Radiographic evaluation & Odds ratio $(95 \% \mathrm{CI})$ & $\mathrm{p}$ value & $\begin{array}{l}\text { Heterogeneity } \\
\text { p value }\end{array}$ & $\begin{array}{l}\text { Heterogeneity } \\
I^{2} \%\end{array}$ & $\begin{array}{l}\text { Number } \\
\text { of TKAs }\end{array}$ & $\begin{array}{l}\text { Number } \\
\text { of studies }\end{array}$ \\
\hline Patellar tilt & $0.886(0.507-1.547)$ & 0.670 & 0.973 & $0 \%$ & 516 & 3 \\
\hline Radiolucent lines & $0.999(0.635-1.574)$ & 0.998 & 0.348 & $10.60 \%$ & 785 & 6 \\
\hline Nonprogressive radiolucent lines & $0.939(0.344-2.563)$ & 0.903 & 0.135 & $50.12 \%$ & 266 & 3 \\
\hline Tibial radiolucent lines & $1.006(0.623-1.625)$ & 0.980 & 0.538 & $0 \%$ & 469 & 3 \\
\hline
\end{tabular}

Table 6. Comparison of rates of osteolysis, loosening, and progressive radiolucent lines

\begin{tabular}{lllll}
\hline Incident & Fixed bearing & Rotating platform & Total & Number of studies \\
\hline Radiographic osteolysis & $0 / 326(0.00 \%)$ & $3 / 331(0.91 \%)$ & $3 / 657(0.46 \%)$ & 4 \\
Radiographic loosening & $0 / 204(0.00 \%)$ & $2 / 210(0.95 \%)$ & $2 / 414(0.48 \%)$ & 4 \\
Progressive radiolucent lines & $1 / 133(0.75 \%)$ & $0 / 133(0.00 \%)$ & $1 / 266(0.38 \%)$ & 3 \\
\hline
\end{tabular}

Table 7. Component alignment

\begin{tabular}{llcllll}
\hline Component alignment & $\mathrm{p}$ value & $\begin{array}{l}\text { Standard difference } \\
\text { in means }(95 \% \mathrm{CI})\end{array}$ & $\begin{array}{l}\text { Heterogeneity } \\
\mathrm{p} \text { value }\end{array}$ & $\begin{array}{l}\text { Heterogeneity } \\
I^{2} \%\end{array}$ & $\begin{array}{l}\text { Number of } \\
\text { TKAs }\end{array}$ & $\begin{array}{l}\text { Number of } \\
\text { studies }\end{array}$ \\
\hline Femoral in AP plane & 0.894 & $-0.024(-0.371$ to 0.324$)$ & 0.166 & $53.43 \%$ & 414 \\
Tibial in AP plane & 0.020 & $0.229(0.035$ to 0.422$)$ & 0.600 & $0 \%$ & 414 & 3 \\
Tibial in sagittal plane & 0.379 & $0.445(-0.547$ to 1.437$)$ & 0.000 & $93.39 \%$ & 414 \\
\hline
\end{tabular}

Table 8. Adverse events

\begin{tabular}{|c|c|c|c|c|c|c|}
\hline Adverse events & $\begin{array}{l}\text { Odds ratio } \\
(95 \% \mathrm{CI})\end{array}$ & $\mathrm{p}$ value & $\begin{array}{l}\text { Heterogeneity } \\
\text { p value }\end{array}$ & $\begin{array}{l}\text { Heterogeneity } \\
I^{2} \%\end{array}$ & $\begin{array}{l}\text { Number of } \\
\text { TKAs }\end{array}$ & $\begin{array}{l}\text { Number of } \\
\text { studies }\end{array}$ \\
\hline Anterior knee pain & $0.901(0.364-2.228)$ & 0.821 & 0.716 & $0 \%$ & 207 & 3 \\
\hline Manipulation for stiffness & $1.628(0.6161-4.301)$ & 0.326 & 0.988 & $0 \%$ & 505 & 4 \\
\hline
\end{tabular}

\section{Results}

\section{Clinical Performance}

There were no differences in clinical scores (The Knee Society scores, Hospital for Special Surgery scores, or SF12 scores) (Table 3), ROM measures (flexion contracture, extension, flexion, or total ROM) (Table 4), or radiographic evaluations for patellar tilt, radiolucent lines, nonprogressive radiolucent lines, or tibial radiolucent lines (these being the variables reported in at least three studies) (Table 5). Contingency analyses of radiographic loosening, osteolysis, and nonprogressive radiolucent lines (using JMP software) did not yield differences between TKAs with rotating-platform and fixed-bearing prostheses (Table 6).

\section{Component Alignment}

Three component alignment variables were reported in at least three studies: femoral alignment in the AP plane and tibial alignment in the AP and the sagittal planes (Table 7). The tibial alignment in the AP plane favored the fixed-bearing groups $(\mathrm{p}=0.020$; standardized mean difference, 0.229 ; 95\% CI, 0.035-0.422), however the effect size was small and was not considered clinically important (Fig. 2).

\section{Adverse Event Rates}

Anterior knee pain and manipulation for stiffness were the only two adverse events reported in at least three studies; 


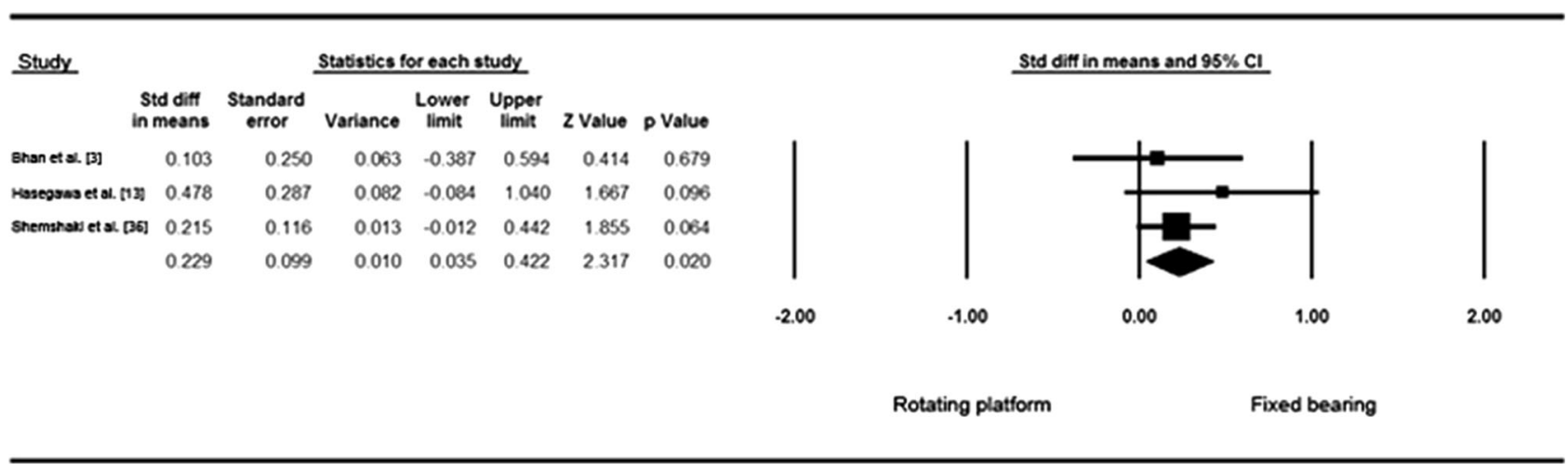

Fig. 2 The meta-analysis of tibial component alignment in the AP plane shows statistical significance in favor of fixed-bearing designs, however, there is no clinical significance. Std diff $=$ standard difference.

Table 9. Revision rates

\begin{tabular}{|c|c|c|c|c|}
\hline Revision & Fixed-Bearing & Rotating-Platform & Total & No. Studies \\
\hline Due to Deep Infection & $2 / 143(1.40 \%)$ & $0 / 145(0.00 \%)$ & $2 / 288(0.69 \%)$ & 3 \\
\hline Due to Loosening & $0 / 187(0.00 \%)$ & $3 / 189(1.59 \%)$ & $3 / 376(0.80 \%)$ & 3 \\
\hline For any reason & $4 / 625(0.64 \%)$ & $4 / 618(0.65 \%)$ & $8 / 1243(0.64 \%)$ & 9 \\
\hline
\end{tabular}

there were no differences between rotating-platform and fixed-bearing groups (Table 8).

\section{Revision Rates}

Revisions resulting from deep infection, loosening, and any reason were not different for rotating-platform and fixedbearing groups (Table 9).

\section{Discussion}

Not all mobile-bearing prostheses are the same; the differences in their geometries influence functioning. Some studies have compared all mobile-bearing subtypes as a single cohort with fixed-bearing designs [4, 5, 33]; some meta-analyses performed the same comparison as a result of the availability of data [17, 24, 28, 37, 38, 41, 42]. Six of the meta-analyses comparing mobile-bearing and fixedbearing prostheses that we reviewed in preparation for our meta-analysis found no significant differences in The Knee Society scores, Hospital for Special Surgery scores, ROM, radiolucent lines, prosthesis-related complications, or patient preference [24, 27, 28, 37, 38, 42]. We therefore sought to determine whether a more granular analysisthat is, looking at one subgroup of mobile-bearing prostheses, the rotating-platform design-might identify important differences that went undetected in analyses that aggregated the results of many different kinds of mobile- bearing prostheses. We found no such differences in terms of clinical performance, component alignment, adverse event rates, or revisions.

Our study has several limitations. First, there is always the possibility of weakness in the source data given our inclusion parameters. For example, it is rather common in the orthopaedic literature to not find a large pool of published articles when you wish to explore a very specific question comparing implant designs, such as the case in our meta-analysis: "Is rotating-platform better than, equal to, or worse than fixed-bearing TKA?" As another example of inherent weakness in source data, there are numerous scoring methods for determining the clinical outcomes of TKAs (The Knee Society, Hospital for Special Surgery, WOMAC, and SF-12), thus clinical outcome data for TKAs are seldom congruent (you could reasonably say that it is rarely congruent); it is difficult to compare clinical outcomes for TKAs because the measuring systems are not directly aligned.

Second, the length of followup for our meta-analysis was approximately 6 years; data from two previous metaanalyses indicate that differences in survivorship are apparent 14 to 15 years after TKA [6, 14]. These two previous meta-analyses compared TKAs with mobilebearing and fixed-bearing prostheses, not TKAs with rotating-platform and fixed-bearing prostheses as we did. For six of our included studies, followups were less than 2 years, therefore our data are not equipped to find possible differences related to long-term failures such as those involving osteolysis or loosening (two of the conditions 
that rotating-platform prostheses are intended to improve) [8, 10-12, 26, 39].

Third, by their nature, meta-analyses create an aggregation of a large number of samples using summary data (means, standard deviations, and other measures of effect size) as opposed to large studies that have individual data points for each individual. This means that meta-analyses may be able to detect very small statistically significant differences; the detection of these differences does not automatically confer clinical significance. It takes clinical judgment to know what to do with these findings. For example, we found a statistically significant difference in tibial alignment in the AP plane favoring TKAs with fixedbearing prostheses ( $\mathrm{p}=0.020$; standardized mean difference, 0.229 ; 95\% CI, 0.035-0.422), but this difference does not meet the judgment to be clinically significant since its effect size is very small.

Two meta-analyses found significantly lower pain scores when comparing TKAs with mobile-bearing and fixed-bearing prostheses $[17,24]$. The Cochrane Review by Jacobs et al. [17] was limited owing to the paucity of randomized controlled trials (two were included): one study found mobile-bearing prostheses to be superior in terms of clinical knee scores and pain subscores only and the other study found no significant differences. Li et al. [24] also found significantly lower pain scores for TKAs with mobile-bearing prostheses in their meta-analysis. Why do their results differ from ours? They used different data sources based on their own inclusion and exclusion criteria. Our inclusion criteria was quite rigorous in an effort to eliminate bias and to eliminate important differences in component design. We believe that we have created a rigorous meta-analysis focusing on a very specific question: "Are there any clinical differences between TKAs with rotating-platform and fixed-bearing prostheses?"

There are two meta-analyses that influenced our decision to conduct our own meta-analysis and to confine it to the rotating-platform subgroup versus the fixed-bearing group. Carothers et al. [6] performed a meta-analysis comparing various mobile-bearing designs and found that the 15-year survivorship of rotating-platform designs (96.4\%) was significantly greater than that of meniscalbearing designs $(86.3 \%)$. Thus, we wondered if by looking at one type of mobile-bearing, specifically the rotatingplatform design, we could discover a difference in clinical performance compared with the fixed-bearing design. Hopley et al. [14] recently performed a meta-analysis comparing a single rotating-platform design with all other designs from the Swedish Knee Registry. They found that there was no significant difference in knee scores at 15year followup but that survivorship at 14 years was greater for the rotating-platform design than for all other designs combined. Their study made us wonder if the differences between rotating-platform and fixed-bearing designs could be determined by performing a meta-analysis of published studies comparing these two designs.

Our analyses of clinical performance (clinical scores, ROM, and radiographic evaluation), component alignment, adverse events, and revisions did not find any clinically important differences between TKAs with rotating-platform and fixed-bearing prostheses. It is possible that the differences may be detectable in a more controlled patient subgroup such as young, active patients with a longer followup. Based on our findings, which agree substantially with those of prior systematic reviews of TKAs with mobile-bearing versus fixed-bearing prostheses, there is no compelling case for either implant design in terms of clinical performance, component alignment, adverse event frequencies, or survivorship. The dataset, limited to approximately 6 years followup, is insufficient to address long-term survivorship and/or failure concerns. Thus, we suggest that implant choices should be made based on other factors, perhaps including cost or surgeon experience.

\section{References}

1. Aggarwal AK, Agrawal A. Mobile vs fixed-bearing total knee arthroplasty performed by a single surgeon: a 4- to 6.5-year randomized, prospective, controlled, double-blinded study. $J$ Arthroplasty. 2013;28:1712-1716.

2. Ball ST, Sanchez HB, Mahoney OM, Schmalzried TP. Fixed versus rotating platform total knee arthroplasty: a prospective, randomized, single-blind study. J Arthroplasty. 2011;26:531536.

3. Bhan S, Malhotra R, Kiran EK, Shukla S, Bijjawara M. A comparison of fixed-bearing and mobile-bearing total knee arthroplasty at a minimum follow-up of 4.5 years. J Bone Joint Surg Am. 2005;87:2290-2296.

4. Callaghan JJ. Mobile-bearing knee replacement: clinical results: a review of the literature. Clin Orthop Relat Res. 2001;392:221225.

5. Callaghan JJ, Insall JN, Greenwald AS, Dennis DA, Komistek RD, Murray DW, Bourne RB, Rorabeck CH, Door LD. Mobilebearing knee replacement: concepts and results. Instr Course Lect. 2001;50:431-449.

6. Carothers JT, Kim RH, Dennis DA, Southworth C. Mobilebearing total knee arthroplasty: a meta-analysis. J Arthroplasty. 2011;26:537-542.

7. Chen LB, Tan Y, Al-Aidaros M, Wang H, Wang X, Cai SH. Comparison of functional performance after total knee arthroplasty using rotating platform and fixed-bearing prostheses with or without patellar resurfacing. Orthop Surg. 2013;5:112117.

8. Chiu KY, Ng TP, Tang WM, Lam P. Bilateral total knee arthroplasty: one mobile-bearing and one fixed-bearing. J Orthop Surg (Hong Kong). 2001;9:45-50.

9. Duval S, Tweedie R. Trim and fill: a simple funnel-plot-based method of testing and adjusting for publication bias in metaanalysis. Biometrics. 2000;56:455-463.

10. Evans MC, Parsons EM, Scott RD, Thornhill TS, Zurakowski D. Comparative flexion after rotating-platform vs fixed-bearing total knee arthroplasty. J Arthroplasty. 2006;21:985-991. 
11. Hanusch B, Lou TN, Warriner G, Hui A, Gregg P. Functional outcome of PFC Sigma fixed and rotating-platform total knee arthroplasty: a prospective randomised controlled trial. Int Orthop. 2010;34:349-354.

12. Harrington MA, Hopkinson WJ, Hsu P, Manion L. Fixed- vs mobilebearing total knee arthroplasty: does it make a difference? A prospective randomized study. J Arthroplasty. 2009;24(6 suppl):24-27.

13. Hasegawa M, Sudo A, Uchida A. Staged bilateral mobile-bearing and fixed-bearing total knee arthroplasty in the same patients: a prospective comparison of a posterior-stabilized prosthesis. Knee Surg Sports Traumatol Arthrosc. 2009;17:237-243.

14. Hopley CD, Crossett LS, Chen AF. Long-term clinical outcomes and survivorship after total knee arthroplasty using a rotating platform knee prosthesis: a meta-analysis. $J$ Arthroplasty. 2013;28:68-77.e1-3.

15. Howick J, Chalmers I, Glasziou P, Greenhalgh T, Heneghan C, Liberati A, Moschetti I, Phillips B, Thornton H, Goddard O, Hodgkinson M; OCEBM Table of Evidence Working Group. The 2011 Oxford CEBM Levels of Evidence (Introductory Document, Background Document, Table). Oxford Centre for EvidenceBased Medicine. Available at: http://www.cebm.net/index. aspx?o=5653. Accessed June 30, 2013.

16. Huang ZM, Ouyang GL, Xiao LB. Rotating-platform knee arthroplasty: a review and update. Orthop Surg. 2011;3:224-228.

17. Jacobs W, Anderson P, Limbeek J, Wymenga A. Mobile bearing vs fixed bearing prostheses for total knee arthroplasty for post-operative functional status in patients with osteoarthritis and rheumatoid arthritis. Cochrane Database Syst Rev. 2004;2:CD003130.

18. Jacobs WC. Comments on the article "clinical and radiological outcomes of fixed- versus mobile-bearing total knee replacement: a meta-analysis". Knee Surg Sports Traumatol Arthrosc. 2010;18:702-703; author reply 704-706

19. Jacobs WC, Christen B, Wymenga AB, Schuster A, van der Schaaf DB, ten Ham A, Wehrli U. Functional performance of mobile versus fixed bearing total knee prostheses: a randomised controlled trial. Knee Surg Sports Traumatol Arthrosc. 2012;20: $1450-1455$.

20. Jawed A, Kumar V, Malhotra R, Yadav CS, Bhan S. A comparative analysis between fixed bearing total knee arthroplasty (PFC Sigma) and rotating platform total knee arthroplasty (PFCRP) with minimum 3-year follow-up. Arch Orthop Trauma Surg. 2012;132:875-881.

21. Jones RE, Huo MH. Rotating platform knees: an emerging clinical standard: in the affirmative. J Arthroplasty. 2006;21(4 suppl 1):33-36.

22. Kalisvaart MM, Pagnano MW, Trousdale RT, Stuart MJ, Hanssen AD. Randomized clinical trial of rotating-platform and fixedbearing total knee arthroplasty: no clinically detectable differences at five years. J Bone Joint Surg Am. 2012;94:481-489.

23. Kim D, Seong SC, Lee MC, Lee S. Comparison of the tibiofemoral rotational alignment after mobile and fixed bearing total knee arthroplasty. Knee Surg Sports Traumatol Arthrosc. 2012; 20:337-345.

24. Li YL, Wu Q, Ning GZ, Feng SQ, Wu QL, Li Y, Hao Y. No difference in clinical outcome between fixed- and mobile-bearing TKA: a meta-analysis. Knee Surg Sports Traumatol Arthrosc. 2012 Dec 2. [Epub ahead of print]

25. Lizaur-Utrilla A, Sanz-Reig J, Trigueros-Rentero MA. Greater satisfaction in older patients with a mobile-bearing compared with fixed-bearing total knee arthroplasty. J Arthroplasty. 2012;27:207-212.

26. Luring C, Bathis H, Oczipka F, Trepte C, Lufen H, Perlick L, Grifka J. Two-year follow-up on joint stability and muscular function comparing rotating versus fixed bearing TKR. Knee Surg Sports Traumatol Arthrosc. 2006;14:605-611.

27. Namba RS, Inacio MC, Paxton EW, Robertsson O, Graves SE. The role of registry data in the evaluation of mobile-bearing total knee arthroplasty. J Bone Joint Surg Am. 2011;93(suppl 3):4850.

28. Oh KJ, Pandher DS, Lee SH, Sung Joon SD Jr, Lee ST. Metaanalysis comparing outcomes of fixed-bearing and mobile-bearing prostheses in total knee arthroplasty. J Arthroplasty. 2009; 24:873-884.

29. Oremus M, Wolfson C, Perrault A, Demers L, Momoli F, Moride Y. Interrater reliability of the modified Jadad quality scale for systematic reviews of Alzheimer's disease drug trials. Dement Geriatr Cogn Disord. 2001;12:232-236.

30. Pagnano MW, Menghini RM. Rotating platform knees: an emerging clinical standard: in opposition. J Arthroplasty. 2006;21(4 suppl 1):37-39.

31. Pandher DS. Re: Comparison of mobile-bearing and fixed-bearing total knee arthroplasty: a prospective randomized study. $J$ Arthroplasty. 2007;22:298; author reply 298-299.

32. Pandher DS, Oh KJ, Lee SH. Comparison between mobilebearing and fixed-bearing knees in bilateral total knee replacements. Int Orthop. 2007;31:131-132.

33. Post ZD, Matar WY, van de Leur T, Grossman EL, Austin MS. Mobile-bearing total knee arthroplasty: better than a fixed-bearing? J Arthroplasty. 2010;25:998-1003.

34. Rahman WA, Garbuz DS, Masri BA. Randomized controlled trial of radiographic and patient-assessed outcomes following fixed versus rotating platform total knee arthroplasty. J Arthroplasty. 2010;25:1201-1208.

35. Raviraj A, Prabhu A, Pai S, Chakravarthy M. Fixed vs mobilebearing total knee arthroplasty: does it make a difference? A prospective randomized study. J Arthroplasty. 2010;25:835, author reply 835 .

36. Shemshaki H, Dehghani M, Eshaghi MA, Esfahani MF. Fixed versus mobile weight-bearing prosthesis in total knee arthroplasty. Knee Surg Sports Traumatol Arthrosc. 2012;20: 2519-2527.

37. Smith H, Jan M, Mahomed NN, Davey JR, Gandhi R. Metaanalysis and systematic review of clinical outcomes comparing mobile bearing and fixed bearing total knee arthroplasty. $J$ Arthroplasty. 2011;26:1205-1213.

38. Smith TO, Ejtehadi F, Nichols R, Davies L, Donell ST, Hing CB. Clinical and radiological outcomes of fixed- versus mobilebearing total knee replacement: a meta-analysis. Knee Surg Sports Traumatol Arthrosc. 2010;18:325-340.

39. Tibesku CO, Daniilidis K, Skwara A, Dierkes T, Rosenbaum D, Fuchs-Winkelmann S. Gait analysis and electromyography in fixed- and mobile-bearing total knee replacement: a prospective, comparative study. Knee Surg Sports Traumatol Arthrosc. 2011;19:2052-2059.

40. Trousdale RT. Mobile vs. fixed-bearing total knee arthroplasty: a clinical and radiologic study. By Woolson and Northrop. $J$ Arthroplasty. 2004;19:1061, author reply 1061.

41. Van der Bracht H, Van Maele G, Verdonk P, Almqvist KF, Verdonk R, Freeman M. Is there any superiority in the clinical outcome of mobile-bearing knee prosthesis designs compared to fixed-bearing total knee prosthesis designs in the treatment of osteoarthritis of the knee joint? A review of the literature. Knee Surg Sports Traumatol Arthrosc. 2010;18:367-374.

42. Wen Y, Liu D, Huang Y, Li B. A meta-analysis of the fixedbearing and mobile-bearing prostheses in total knee arthroplasty. Arch Orthop Trauma Surg. 2011;131:1341-1350. 